\title{
Sport, Alcohol and
}

Social Incuiry

A Global Cocktail 
SPORT, ALCOHOL AND SOCIAL INQUIRY 
This page intentionally left blank 


\title{
SPORT, ALCOHOL AND SOCIAL INQUIRY: A GLOBAL COCKTAIL
}

\author{
EDITED BY \\ SARAH GEE \\ University of Windsor, Canada
}

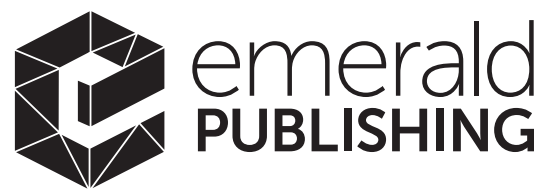

United Kingdom - North America - Japan India - Malaysia - China 
Emerald Publishing Limited

Howard House, Wagon Lane, Bingley BD16 1WA, UK

First edition 2020

Copyright (C) 2020 Emerald Publishing Limited

\section{Reprints and permissions service}

Contact: permissions@emeraldinsight.com

No part of this book may be reproduced, stored in a retrieval system, transmitted in any form or by any means electronic, mechanical, photocopying, recording or otherwise without either the prior written permission of the publisher or a licence permitting restricted copying issued in the UK by The Copyright Licensing Agency and in the USA by The Copyright Clearance Center. Any opinions expressed in the chapters are those of the authors. Whilst Emerald makes every effort to ensure the quality and accuracy of its content, Emerald makes no representation implied or otherwise, as to the chapters' suitability and application and disclaims any warranties, express or implied, to their use.

\section{British Library Cataloguing in Publication Data}

A catalogue record for this book is available from the British Library

ISBN: 978-1-78769-842-0 (Print)

ISBN: 978-1-78769-841-3 (Online)

ISBN: 978-1-78769-843-7 (Epub)

ISSN: 1476-2854 (Series)

\section{ISOQAR certified}

Management System,

awarded to Emerald

for adherence to

Environmental

standard

ISOQAR

ISO 14001:2004.

\section{REGISTERED}

Certificate Number 1985

ISO 14001

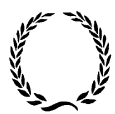

INVESTOR IN PEOPLE 


\section{CONTENTS}

About the Contributors

$v i i$

Introduction: Contextualizing the Sport and Alcohol

Relationship for Social Inquiry

Sarah Gee

Chapter 1 Real Men, Himbos and Bros: Continuity and Change in the Portrayal of Masculinities in Sport-dirtied Beer Advertising

Christopher J. Finlay and Lawrence A. Wenner

Chapter 2 Contemporary Trends in Sport, Beer Advertising and Masculinity: New Zealand's Speight's 'Southern Man' 2.0 Steven J. Jackson and Sarah Gee

Chapter 3 Examining the Impact of a New Beer Sponsor on Attitudes and Behavioural Intentions toward American College Football Teams

Terry Eddy, Sarah Gee and Lamar Reams

Chapter 4 Tactical Drinking in a Female University

Kendo Club

Kate Sylvester and Brent McDonald

Chapter 5 Sport, Alcohol and Older Athletes

Catherine Palmer

Chapter 6 Brazil's Legislation of Alcohol Consumption by Sports Fans and the 2014 FIFA World Cup

Bárbara Schausteck de Almeida and Wanderley Marchi Júnior

Chapter 7 Alcohol and Sport in France: An Unsettled Field

Guillaume Bodet, Guillaume Routier and Stéphan Fuchs 
Chapter 8 The Swedish Alcohol-Sport Paradox: Sport's Drinking Problem and the Politics of Forwarding

Cecilia Stenling and Josef Fahlén

Chapter 9 Researching Drinking Cultures in Sport: Making Difficult Ethical Decisions

Carwyn Jones, David Brown and Marc Harris

Chapter 10 'Fun Sponge!' and Other Conjectures: Conducting Field Research in Sport and Alcohol

Sarah Gee

Index 


\section{ABOUT THE CONTRIBUTORS}

Guillaume Bodet is a Professor of Sport Management and Marketing at the University Claude Bernard Lyon 1 (University of Lyon) and a member of the Laboratory on Vulnerabilities and Innovation in Sport (L-VIS). His research interests deal with consumer behaviours in relation to sport objects (products, services, brands and events).

David Brown is a Reader in the Sociology of Sport and Physical Culture at Cardiff Metropolitan University. He has published widely on issues relating to the body-self-society relationship in sport and physical culture.

Terry Eddy is an Associate Professor of Sport Management at the University of Windsor, Canada. His research centres around sport marketing, particularly consumers' responses to, and behaviours towards, sponsorship and social media marketing.

Josef Fahlén is an Associate Professor at the Department of Education, Umeå University, Sweden, and Visiting Professor at the Norwegian School of Sport Sciences in Oslo. In his research, Fahlén focuses on the intersection between sport policy and the organization of sport.

Christopher J. Finlay is an Associate Professor in the Department of Communication Studies at Loyola Marymount University in Los Angeles, California. His research interests include global communication, digital media and policy, media industries and sports media.

Stéphan Fuchs is an Assistant Professor in sport marketing at the University Claude Bernard Lyon 1 (University of Lyon) and a member of the Laboratory on Vulnerabilities and Innovation in Sport (L-VIS). His research focuses on various topics to better understand the behaviour of stakeholders in sporting contexts. His latest publications focus on activation of Olympic and Paralympic sponsorship and on the relationships between marketing and alcohol.

Sarah Gee is an Assistant Professor in the Department of Kinesiology at the University of Windsor, Canada. Her current research interests seek to examine the mutually constitutive link between alcohol sponsorship and the experiential politics of athletes' sport-related drinking.

Marc Harris a $\mathrm{PhD}$ candidate at Cardiff Metropolitan University, United Kingdom. His research explores the social and cultural determinants of excessive alcohol use among student athletes. 
Steven J. Jackson is a Professor at the University of Otago, New Zealand and a Visiting Professor at the University of Johannesburg, South Africa. A pastPresident of the International Sociology of Sport Association, Steve's research focuses on globalization, media and national identity.

Carwyn Jones is a Professor of Sport Ethics at Cardiff Metropolitan University. He has published books and articles on a broad range of ethical issues in sport including the relationship between alcohol and sport.

Wanderley Marchi Júnior is a Full Professor in the Department of Physical Education and Department of Social Sciences at Federal University of Parana, Brazil. His current research interests focus on the theoretical references of sport sociology and Latin American sociocultural studies of sport.

Brent McDonald is a Senior Lecturer in the College of Sport and Exercise Science at Victoria University, Australia. His research focuses on the role of sport in migration and settlement processes, inclusion and identity politics, and sport in Japanese education.

Catherine Palmer is Professor of Sociology in the School of Social Sciences at the University of Tasmania. Her current research examines women and alcohol in Australian sport and the phenomenon of fitness philanthropy.

Lamar Reams is an Associate Professor and Graduate Program Director of Sport Management at Old Dominion University in Norfolk, Virginia. His primary areas of research interest include sport consumer behaviour, particularly in the context of combat sports and sport sponsorship.

Guillaume Routier is an Assistant Professor in Sociology of Sport at the University Claude Bernard Lyon 1 (University of Lyon) and a member of the Laboratory on Vulnerabilities and Innovation in Sport (L-VIS). His current research focuses on various topics aimed at better understanding sports cultures: participation in sport and the end of a sports career; the diet of ultra trail runners; the relationship between sport and alcohol.

Bárbara Schausteck de Almeida is an Independent Scholar who undertook her $\mathrm{PhD}$ in Sociology of Sport at Universidade Federal do Paraná, Brazil. Her current research interests use Sociology and Political Science references to understand mega-events and sport in Brazil.

Cecilia Stenling is an Associate Professor at the Department of Education, Umeå University, Sweden. Her research focuses on the processes that take place in the nexus between public sport policy and the norms, values and practices that characterize sport's internal organizing and governance.

Kate Sylvester examined Japanese university kendo practices for women in her $\mathrm{PhD}$ thesis. Kate has practiced kendo for 26 years and represented her country 
at 7 World Kendo Championships. Her research focuses on kendo, gender politics and Japanese university sport.

Lawrence A. Wenner is Von der Ahe Professor of Communication and Ethics in the College of Communication and Fine Arts and the School of Film and Television at Loyola Marymount University, USA. He is founding Editor-inChief of the scholarly journal Communication and Sport, an author of nine books and over 140 scholarly journal articles and chapters that focus on media, popular culture, sport and commodification. 
This page intentionally left blank 


\title{
INTRODUCTION:
}

\section{CONTEXTUALIZING THE SPORT AND ALCOHOL RELATIONSHIP FOR SOCIAL INQUIRY}

\author{
Sarah Gee
}

Sport and alcohol are two highly commodified and widely popular social lubricants, whose relationship is rather paradoxical. On the one hand, the link between them has been characterized by scholars within the sociology of sport, sport management and policy studies as a 'nexus' (Palmer, 2011), a 'dyad' (McDaniel \& Mason, 1999), a 'partnership' (Munro, 2000) and, by way of the title of this book, A Global Cocktail. On the other hand, it has been critiqued as 'problematic' (Jones, 2010), culturally hypocritical (Johnson, 1988), a 'cultural irony' (Wenner, 1991) and a 'contested terrain' (Cody \& Jackson, 2016). Irrespective of how it is framed, there is an underlying acknowledgement that an association, connection or relationship does exist. In addition, there are a range of different perspectives, stakeholders, complexities and contradictions that contribute to understanding the physical, symbolic, ideological and ethical dimensions of this relationship.

It is argued that alcohol is not an ordinary commodity (Babor et al., 2010) with regards to its harmful consequences to a consumer's health and the potential for alcohol-related harm to those around them. Yet, sport plays a key role in normalizing alcohol because it is a globally popular, highly visible and influential part of society; it attracts large audiences; and professional athletes are commonly associated with youth, health and nationalism. Indeed, sport and alcohol are often consumed simultaneously, by sports fans and participants, in front of (and through) a televised sports broadcast, in the locker rooms of many sports venues following games, and in sports stadiums.

The economic, political and cultural impact of the sport-alcohol relationship is undeniable. For example, formalized sport sponsorship investment by the top 30 global alcohol brands is estimated to be worth $\$ 764.5$ million USD (Sportcal,

Sport, Alcohol and Social Inquiry

Research in the Sociology of Sport, Volume 14, 1-8

Copyright (C) 2020 Emerald Publishing Limited

All rights of reproduction in any form reserved

ISSN: 1476-2854/doi:10.1108/S1476-285420200000014001 
2018) and becomes even larger when combined with smaller and in-kind product sponsorships from regional/local alcohol brands and drinking establishments (e.g. pubs/taverns). Arguably, the exposure that alcohol brands receive through a sponsorship deal is unparalleled given the vast following of sports fans and viewership (e.g. alcohol logos on jerseys and/or at sporting venues/grounds, alcohol sales at sports venues). But sponsorships also offer opportunities for sports teams, leagues, events to tap into new markets. A prime example is Tennis Australia's 2018 five-year partnership with Luzhou Laojiao, a Chinese distillery, rumoured to be worth over $\$ 85$ million AUD (Walsh, 2018). This agreement was pivotal in rebranding the Australian Open as the grand slam of the Asia-Pacific region for the duration of the sponsorship contract and doubles the broadcast hours of the event in China. In addition to formalized sponsorships, informal associations of the alcohol industry with sport also occur. For example, during the 2019 Super Bowl, which is the championship game for the National Football League in the United States, the cost for a 30second television commercial averaged just over \$5 million USD (Huddleston, 2019). During the broadcast, four beer brands (Budweiser, Stella Artois, Bud Light, Michelob Ultra) and a seltzer brand (Bon \& Viv) aired a total of nine different advertisements; the highest number compared to any other industry (e.g. automobiles, telecommunications, Internet services) (Ads of the World, 2019). Even still, almost all forms of (men's) sport are entangled with alcohol sponsorship, moving beyond traditional sports to the newest platform of eSports. In 2019, Anheuser-Busch InBev (AB InBev) became the official beer partner for the Overwatch League, a global eSport league with teams in the UK, China, South Korea, USA, Canada and France, and other worldwide locations. According to João Chueiri, Senior Vice-President of consumer connections marketing at AB InBev, "This partnership provides us with an opportunity to engage with a new segment of legal-drinking-age fans and align our brands with one of the most exciting eSports properties out there right now" (Businesswire, 2019). From these examples alone, this suggests that the financial value of the link between sport and alcohol is exceptionally lucrative and mutually 'symbiotic' (O'Brien \& Kypri, 2008), and yet problematic due to the appeal of professional (e)sport to young (under age) viewers.

As an example of the political dimension of the sport-alcohol relationship, Brazil experienced the iron fist of Fédération Internationale de Football Association (FIFA; the global governing body for football/soccer) to change a law that prohibited the sale of alcohol in Brazilian sports stadiums since 2003. FIFA's World Cup tournament was hosted by Brazil in 2014, and FIFA wanted the law changed to protect the commercial rights of one of its World Cup Sponsors, Budweiser (an American beer brand). According to FIFA General Secretary, Jerome Valcke,

\footnotetext{
Alcoholic drinks are part of the FIFA World Cup, so we're going to have them. Excuse me if I sound a bit arrogant but that's something we won't negotiate. The fact that we have the right to sell beer has to be part of the law. (BBC News, 2012a)
}

Moreover, this law change was part of the conditions stipulated by FIFA when Brazil was awarded the 2014 World Cup. In June 2012, the Congress and 
President of Brazil eventually passed the highly publicized and nicknamed 'Budweiser Bill' (BBC News, 2012b). Indeed, this case highlights the power of one global governing sports body to influence amendments to pre-existing nation-state legislation to preserve alcohol sponsorship rights to sports events.

Poltical complexities continue with FIFA's decision to award the 2022 World Cup hosting rights to Qatar, which has been questioned for a number of reasons, one of which is the restrictive alcohol laws of the conservative Muslim country (Dun, 2014). As Palmer (2019, p. 280) states: "While the consumption of alcohol is not illegal for foreigners in Qatar, drinking in public or being drunk in a public space - often a feature of media coverage of fans' experiences of sporting mega events - can result in monetary fines, deportation, or even prison sentences." In a similar fashion to what happened in Brazil for the 2014 World Cup, it is likely that FIFA will seek to exert significant pressure on Qatar to relax the restrictive alcohol laws (e.g., taxes as well as where/when/how alcohol can be purchased and consumed) for the benefit of FIFA, their sponsors, and to attract fans to experience the tournament. This is particularly intriguing given the recent implementation of a "sin tax" on alcohol in Qatar, doubling the costs to purchase alcohol (Radnofsky, 2019). While Qatar agreed to FIFA's regulations and guidelines for the World Cup, officials from the nation have stated that there's no guarantee that they will bow to FIFA's pressures, particularly when it comes to the issue of alcohol, and they will explore creative solutions to fulfill their obligations without compromising on their Islamist values and traditions (Hartmann, 2014). Potential compromises include: "cheaper alcohol prices, an extension of hotel happy hours and more locations where it will be sold during the World Cup" (Ingle, 2019). Qatari tournament organizers acknowledge a need to accommodate fan expectations with respect to alcohol, but maintain that "alcohol is not part of our culture. . however, hospitality is" (Ingle, 2019).

Alcohol brands continue to pursue increasingly sophisticated ways to embed their brands and products into the social fabric of our society. Beer companies are strategically positioning their brands as cultural advocates for significant social inequality issues around the world and within sport. Consider the following examples:

- In 2015, Stella Artois partnered with Water.org for a campaign entitled, 'Buy a Lady a Drink'. The campaign addresses the global water crisis, where hundreds of millions of people in the developing world lack access to clean drinking water. According to Stella's parent company, Anheuser-Busch InBev, the global water crisis 'disproportionally affects women and children, who collectively spend millions of hours a day collecting water instead of working, attending school or caring for their families' (AB InBev, 2018). Actor Matt Damon, spokesperson for the campaign, declares that the public can make a significant difference in the lives of these women who walk for water by simply purchasing a Stella Artois chalice (the famous Stella drinking glass), which would supply five years of clean drinking water for someone in the developing world. The 2019 version of this campaign, 'Pour it Forward', is a play on the meaning of the well-known expression, pay it forward, suggesting that those 
who buy the chalice are participating in an act of kindness for someone else, creating a ripple effect: 'with access to clean water, women can care for their families, families can earn an income and pursue their dreams' (Stella Artois, 2019). A critique by National Public Radio about the campaign fact-checks the claim about the costs of clean water (NPR, 2018). They argue that the $\$ 3$ (agreed donation from Stella) of the total \$13 (the cost to buy the chalice) does not actually go towards buying a well or the provision of jugs of water. Instead, Water.org facilitates microloans to 'lend people small amounts of money so they can pay to get water' (NPR, 2018). Ultimately, this example highlights the contradictions of the production and consumption of an alcohol product that requires vast amounts of water to produce.

- While alcohol sponsorship of women's sport has, to date, been fairly limited, female consumers have been recognized as a major target market by the alcohol industry. Therefore, it is highly likely that women's sport will become an increasingly strategic vehicle for alcohol sponsorship. Women's sport is not only attracting more players but also calling for increased and equal pay, media coverage and sponsorship of elite female teams and leagues. In 2019, Budweiser aired three public relations commercials in North America (two related to women's soccer: 'We won't stop watching' and 'It's worth supporting', one linked with women's hockey: 'This game is for us all. \#forthegame') that served to raise awareness about prominent issues facing women's professional sport. The soccer ads feature voiceovers by Brandi Chastain and Megan Rapinoe. The hockey ad captures short clips of wellknown female hockey players Jayna Hefford, Marie-Philip Poulin, Natalie Spooner and Cassie Campbell, as well as notable sports media and hockey personalities Don Cherry, Ron Maclean, Sid and Tim from Sportsnet reciting lines from Canadian country and folk singer-songwriter Stompin' Tom Connor's song Good Old Hockey Game. The three ads spotlight the issue of social and corporate support for women's teams and leagues through two 2019 events: (1) the incredible support for the US national women's team, and their celebrated success, at the women's football World Cup against a backdrop of poor spectator attendance at games in their own national league and (2) the collapse of the Canadian Women's Hockey League despite the sport being Canada's national game. Using these platforms, Budweiser challenges other brands and industries to come forward to sponsor women's sport.

The look, sound and feel of these ads parallel the same serious yet 'touchyfeely' sensations that are often assimilated with public service announcements that promote good citizenship, but with an obvious corporate twist. These types of campaigns publicly broadcast the attempts of alcohol brands to popularize their stewardship of such issues and become known as key activists to: introduce change, make an impact on issues of inequality, and grow women's sport. This is situated in a larger social, political-economic climate where equivalent forms of (financial) support from governments and other sport organizations is minimal or non-existent. 
Beyond specific alcohol brands' affiliations (either formally or informally) with sport, it is also important to consider some examples that illuminate the ways in which sport-related drinking has become normalized:

- Many sports fans enjoy consuming alcohol as part of their sport viewing experience (live or televised). Some sports venues (e.g. some university stadia in the United States, and professional stadia in France, Brazil and other countries) seek to relax regulations that currently ban the sale of alcohol at sporting events within these settings. However, in doing so, the management of the sale and supply of alcohol creates further complexities that introduce the need for security and other policies to ensure safe and responsible consumption. Indeed, the nature of some sports events (through the media) propagates the consumption of alcohol as part of the event experience not only to sell tickets to the event but also to heighten the atmosphere of the event (Gee, 2014).

- In summer 2019, Aaron Rogers, quarterback for the Green Bay Packers from the National Football League (NFL) in the United States, was filmed while attempting to chug a beer at a playoff game for the Milwaukee Bucks (a team in the National Basketball Association). He was not able to finish his pint, but the national broadcast of the game and telecast of Rogers' pathetic effort sparked an informal beer guzzling competition among other quarterbacks. Mitch Trubisky, Patrick Mahomes and Baker Mayfield were captured on stadium big screens and television broadcasts shaming Rogers with their superior beer chugging skills while attending hockey and baseball games as spectators in the crowd. Matthew Stafford, Josh Allen and Tom Brady were also recorded gulping beers and posted on social media.

- Sports teams often celebrate championship wins with alcohol. Some of these celebrations are in the public sphere; for example, Formula One winners spray each other with champagne on the winner's podium. Other celebrations occur in dressing rooms away from the public eye. However, in recent years the media has been granted access to capture these commemorative moments. Video clips and photos reporting on these moments feature athletes showering each other with alcohol while wearing ski goggles, suggesting that this is a planned or expected form of behaviour after sporting success. In 2010, Canada's women's ice hockey team won a gold medal at the Vancouver Winter Olympic Games. Several of the athletes left the locker room and took the celebration to the ice drinking beer (Molson Canadian; a Team Canada sponsor), champagne and smoking cigars. Juxtaposed against Olympic values, the athletes were scorned for their irresponsible and unethical actions (Edwards, Jones, \& Weaving, 2013).

Paradoxes around athlete drinking practices arise when particular kinds of 'fun' or 'trivial' drinking are framed against media reports that name and shame athletes (predominantly male) for charges of drunk driving, aggravated assault and other misconducts due to excessive alcohol consumption. Moreover, as recipients of alcohol sponsorship (in some countries), and visible/televised consumers, athletes are often seen as tacit or active endorsers of alcohol. But, what roles and responsibilities do their sports teams and organizations play by prioritizing commercial interests over athlete welfare? 
While the pairing of sport and alcohol has a long history (Collins \& Vamplew, 2002), discussions about the appropriateness and implications of alcohol sponsorship of sport have reached new heights and engage a range of sectors and interest groups. On one side, medical and public health advocates believe that sponsorship and marketing through sport contribute to excessive consumption. These individuals and groups lobby for greater restrictions, including a ban on alcohol sponsorship of sport to help reduce alcohol-related harms, similar to the Loi Évin in France (Casswell, 2014; Kypri, O’Brien, \& Miller, 2009). ${ }^{i}$ On the other side, many sports clubs and organizations not only support alcohol funding of their teams, leagues and events, but they argue that they would struggle to survive financially without it (Braillard, 2016; SportNZ, cited in Ministry of Health NZ, 2014). Moreover, the alcohol industry refutes any causal link between marketing strategies, such as sponsorship, and drinking behaviour (Smith \& Foxcroft, 2009). Taken together, debates concerning the sport and alcohol relationship are shrouded with degrees of financial, organizational, social, cultural, ethical and even behavioural approaches and implications.

This is not the first book specifically dedicated to unveiling the sport and alcohol relationship. There are a number worth mentioning as they provide a foundation for current - including some of the themes in this book - and future research. Sperber's (2000) Beer and Circus was among the first to offer a critical examination of the intersection of sport, alcohol and higher education in the United States. In particular, Sperber focuses on the party culture that surrounds college athletics and the role this culture has played in eroding undergraduate education at many large American universities. Collins and Vamplew's (2002) $M u d$, Sweat and Beers explores the enduring uneasy alliance between sport and alcohol. Their cultural history of drinking and sport examines the roles that masculinity, class and regional identity play in alcohol consumption across a wide range of sporting contexts. Wenner and Jackson's (2009) Sport, Beer, and Gender interrogates the cultural bonding of sport and beer in promotional culture and to better understand this connection through its characterization and strategic positioning of gender through their conception of the 'holy trinity' of sport, beer and gender. Palmer's (2015) monograph, Rethinking Drinking and Sport, raises key questions and details insightful considerations on broad complexities related to contemporary sport and alcohol consumption, challenging a rethink of the role that sport and alcohol play in our social lives. Jones' (2016) Sport and Alcohol: An Ethical Perspective establishes a thoroughgoing critical stance on different aspects of the relationship between sport and alcohol. Referring to a drinking ethos, Jones characterizes individual sporting cultures or subcultures by patterns of drinking. In addition to these books, and this volume, there are numerous journal articles and book chapters (including a special issue of the International Review for the Sociology of Sport in 2014) that collectively contribute to a growing critical mass of evidence-based scholarly research that continues to espouse the cultural and contextual roles of sport and alcohol in contemporary society.

The chapters in this volume expand and strengthen the literature to further contextualize the sport and alcohol relationship and explore a range of intricacies, issues and controversies. This book brings together expert and emerging scholars who focus on a particular case or context that relates to promotional culture 
(Chapters 1, 2 and 3), identity politics (Chapters 4 and 5), policy legislation and regulation (Chapters 6, 7 and 8) or research design and methodological considerations (Chapters 9 and 10). However, these accounts are not intended to be exhaustive or complete. Indeed, there are other identities (e.g. Indigenous, nondrinkers), national regulatory policies, advertising campaigns and sponsorship arrangements that warrant attention and examination, and students and scholars alike are encouraged to use the this book to set the course for future works. As evidenced by the chapters in this book, a social inquiry of sport and alcohol is not centralized in one discipline, but draws from media studies, cultural studies, gender studies, social policy studies, sport management and marketing, and others. Thus, the sociological research included in this volume is deliberately broad in nature to address some of the complex social phenomena that link to an entrenched, naturalized and global culture of alcohol promotion and consumption within sport. This volume is intentionally global in its scope (in both chapter topics as well as contributors) and, as such, for some authors English is a second language. Therefore, the manner in which authors have written their chapters gives a certain voice to their contribution in a larger conversation wherein each chapter adds a truly valuable 'spirit' to distilling A Global Cocktail of sport and alcohol.

\section{NOTE}

i. Implemented in 1991 to protect against risks and harm to public health, one of the most significant outcomes of Loi Évin is that no alcohol advertising is allowed on television or in cinemas, and alcohol sponsorship of cultural and sport events is prohibited (Rigaud \& Craplet, 2004). In addition, any advertising that is permitted is restricted to factual information about the product and must include a health message, disclosing " "l'abus d'alcool est dangereux pour la santé" (alcohol abuse is dangerous to health)' (Babor et al., 2010). Loi Évin remains, for many, a blueprint for regulatory practices against alcohol advertising and sponsorship.

\section{REFERENCES}

AB InBev. (2018). Stella's Buy a Lady a Drink program. Retrieved from https://www.ab-inbev.com/ news-media/water-stewardship/stellas-buy-a-lady-a-drink-program.html

Ads of the World. (2019). 2019 super bowl commercials. Retrieved from https:// www.adsoftheworld.com/collection/2019_super_bowl_commercials\#

Babor, T., Caetano, R., Casswell, S., Edwards, G., Giesbrecht, N., Graham, K., ... Rossow, I. (2010). Alcohol: No ordinary commodity. Oxford: Oxford University Press.

BBC News. (2012a). Brazil World Cup beer law signed by President Rousseff. Retrieved from https:// www.bbc.co.uk/news/world-latin-america-18348012

BBC News. (2012b). Beer "must be sold" at Brazil World Cup, says Fifa. Retrieved from https:// www.bbc.com/news/world-latin-america-16624823

Braillard, T. (2016). Grande Conférence sur le Sport Professionnel Français. Ministère de la ville, de la jeunesse et des sports. Retrieved from http://www.sports.gouv.fr/IMG/pdf/confsportpro_2016_ rapport_hd4.pdf

Businesswire. (2019). Overwatch League ${ }^{\mathrm{TM}}$ Names AB InBev as Official Beer Sponsor. Retrieved from: https://www.businesswire.com/news/home/20190426005125/en/

Casswell, S. (2014). Profits or people? The informative case of alcohol marketing. New Zealand Medical Journal, 127(1406), 87-92.

Cody, K., \& Jackson, S. (2016). The contested terrain of alcohol sponsorship of sport in New Zealand. International Review for the Sociology of Sport, 51(4), 375-393.

Collins, T., \& Vamplew, W. (2002). Mud, sweat and beers. London: Bloomsbury. 
Dun, S. (2014). No beer, no way! Football fan identity enactment won't mix with Muslim beliefs in the Qatar 2022 World Cup. Journal of Policy Research in Tourism, Leisure and Events, 6(2), 186-199.

Edwards, L., Jones, C., \& Weaving, C. (2013). Celebration on ice: double standards following the Canadian women's gold medal victory at the 2010 Winter Olympics. Sport in Society, 16(5), 682-698.

Gee, S. (2014). Sport and alcohol consumption as a neoteric moral panic in New Zealand: Context, voices and control. Journal of Policy Research in Tourism, Leisure and Events, 6(2), 153-171.

Hartmann, C. (2014). Qatar Vows To Be "Creative" With Alcohol At 2022 World Cup But Offers No Guarantee. Retrieved from: https://finance.yahoo.com/news/qatar-vows-creative-alcohol-2022012600035.html

Huddleston, T. (2019). This is how much it costs to air a commercial during the 2019 Super Bowl. CNBC. Retrieved from https://www.cnbc.com/2019/01/30/how-much-it-costs-to-air-acommercial-during-super-bowl-liii.html

Ingle, S. (2019). Alcohol set to be subsidised and more available at 2022 World Cup in Qatar. Retrieved from: https:/www.theguardian.com/football/2019/sep/26/alcohol-2022-football-world-cup-qatar

Johnson, W. O. (1988). Sports and suds. Sports Illustrated, August 8, pp. 68-82.

Jones, C. (2016). Sport and alcohol: An ethical perspective. London: Routledge.

Jones, S. (2010). When does alcohol sponsorship of sport become sports sponsorship of alcohol? A case study of developments in sport in Australia. International Journal of Sports Marketing \& Sponsorship, 11(3), 250-261.

Kypri, K., O’Brien, K., \& Miller, P. (2009). Time for precautionary action on alcohol industry funding of sporting bodies. Addiction, 104(12), 1949-1950.

McDaniel, S. R., \& Mason, D. (1999). An exploratory study of influences on public opinion towards alcohol and tobacco sponsorship of sporting events. Journal of Services Marketing, 13(6), 481-499.

Ministerial Forum on Alcohol Advertising and Sponsorship. (2014). Ministry of Health NZ. Retrieved from http://www.health.govt.nz/system/files/documents/publications/group_submissions_ folder_10.pdf. Accessed on November 20, 2014.

Munro, G. (2000). Challenging the culture of sport and alcohol. International Journal of Drug Policy, 11(3), 199-202.

National Public Radio. (2018). Fact-checking Matt Damon's clean water promise in a Super Bowl ad. Retrieved from https:/www.npr.org/sections/goatsandsoda/2018/02/02/582664769/fact-checkingmatt-damons-clean-water-promise-in-a-super-bowl-ad

O’Brien, K. S., \& Kypri, K. (2008). Alcohol industry sponsorship and hazardous drinking among sportspeople. Addiction, 103(12), 1961-1966.

Palmer, C. (2011). Key themes and research agendas in the sport-alcohol nexus. Journal of Sport \& Social Issues, 35(2), 168-185.

Palmer, C. (2015). Rethinking drinking and sport. Farnham: Ashgate.

Palmer, C. (2019). Sports, beer, and promotional culture. In J. Maguire, M. Falcous, \& K. Liston (Eds.), The Business and Culture of Sports: Society, Politics, Economy, Environment (pp. 273-283). Farmington Hills, MI: Macmillan.

Radnofsky, C. (2019). Qatar "sin tax" suddenly doubles the cost of alcohol. Retrieved from: https:// www.nbcnews.com/news/world/qatar-sin-tax-suddenly-doubles-cost-alcohol-n953731

Rigaud, A., \& Craplet, M. (2004). The Loi Evin: A French exception. Globe, 1(2), 33-36.

Smith, L. A., \& Foxcroft, D. R. (2009). The effect of alcohol advertising, marketing and portrayal on drinking behaviour in young people: Systematic review of prospective cohort studies. BMC Public Health, 9, 51. doi:10.1186/1471-2458-9-51

Sperber, M. (2000). Beer and circus: How big-time college sports is crippling undergraduate education. New York, NY: Henry Holt and Company.

Sportcal. (2018). Sponsorship sector report: Alcoholic beverages. London: Sportcal.

Stella Artois. (2019). Retrieved from https://www.stellaartois.com/en_us/water.html

Walsh, C. (2018). Australian Open's record Chinese sponsorship deal. The Weekend Australian. Retrieved from https://www.theaustralian.com.au/sport/tennis/australian-opens-record-chinesesponsorship-deal/news-story/1f9bcc069744ec962847c0987cfb640a

Wenner, L., \& Jackson, S. J. (2009). Sport, beer, and gender. Zurich: Peter Lang Publishers.

Wenner, L. A. (1991). Promotional culture: Advertising, ideology, and symbolic expression. London: SAGE Publications. 